\author{
Available online at https://www.rjtl.org \\ Volume: 1, Issue: 1, 11-14, 2020 \\ ISSN: 2708-3632 \\ DOI: https://doi.org/10.46590/rjtl.2020.010102
}

\title{
Studies on Effect of Alkali Treatment on Mechanical Properties of Multi-Layer Viscose / Flax Composites.
}

\author{
Gnanavel P \\ Department of Textile Engineering, Axum University, Ethiopia.
}

\section{$\underline{\text { Paper Status }}$}

Received : March 2020

Accepted : April 2020

Published : May 2020

Corresponding Author

Gnanavel P

geepeeinfo525@gmail.com

\begin{abstract}
Composite fabrics consist of numerous structural components and are united into a single structure. The applications of composite fabrics are versatile and it is depending upon the constituent materials and the mechanical properties are changed by the constituents. The study of mechanical properties of composite fabrics such as flexural rigidity, tensile strength, impact became very essential to understand the suitability of application in various areas. In this study the various mechanical properties are studied by treating with alkali and resins. The results of mechanical properties were analyzed and compared with treated and untreated. The results show that alkali treated fabrics have enhanced mechanical properties.
\end{abstract}

Keywords: Alkali, Composites, Mechanical, Resin

Citation: Gnanavel P, Studies on Effect of Alkali Treatment on Mechanical Properties of Multi-Layer Viscose/Flax Composites., Journal of Textile, Fashion and Apparel, 1(1), 11-14, 2020

\section{INTRODUCTION}

Natural fibers are renewable fibers which are obtained from plants or animals, which plays the major role in manufacturing of dress material, curtains and other industrial textile products. The industrial textile products are obtained by converting the textile materials into composites, which are produced by combining the properties of different materials. The textile materials in the form of fibres/yarns have poor mechanical properties, but once they converted in the form of fabrics or composites, which exhibits excellent mechanical properties. The mechanical properties such as tensile, flexural and impact of banana / jute / banana composite fabrics were analyzed by [1] and it was found that the tensile and flexural strength of composites are higher than individual composites.

The plain woven twill weave jute fabric composites were analyzed by [2]. They found that the fabric laying at an angle plays the important role to achieve high mechanical properties. The mechanical properties of alkali treated ramie/poly lactic acid composites were analyzed and it was absorbed that the fabric composites have better tensile strength, tensile modulus and higher flexural strength. The good interfacial adhesion was also achieved [3]. The optimum composite tensile strength was achieved by setting the immersion temperature ranging at $30^{\circ} \mathrm{C}$ to $80^{\circ} \mathrm{C}$ and alkali concentration of $6 \%$ for the duration of 24 hours.

The maximum textile, flexural strength and impact energy were obtained in axial oriented laminates was found by [5] in flax and polypropylene composites. The degree of mechanical reinforcement that can be obtained by the introduction of glass fibers in bio-fiber (silk fabric)-reinforced epoxy composites. It was observed that the mechanical properties of composite increases with the increase in the weight fraction of reinforcement content to the maximum extent. The water uptakes of hybrid composites are observed to be less than that of un hybridized composites [6].

In this research work an attempt was made to produce the composite fabrics from viscose and flax fibres. Generally, the cellulosic fibres shows increase in strength with alkali treatment. This alkali treated cellulosic fabrics are coated with epoxy resin and are binded together to form multi-layer fabrics. These multi-layer fabrics are widely used in the interiors of automobiles, wall decors and other applications. 


\section{MATERIALS AND METHODS}

\subsection{Materials}

The English count $16^{\mathrm{s}}$ of flax and viscose yarns were purchased in the region of Tiruppur, India and the epoxy resin was procured from Chennai, India. The chemical sodium hydroxide was used to swell the cellulosic fibre, which was procured in Erode, India.

\subsection{Methods}

The fabric was made from viscose as warp yarn and flax as weft yarn woven by automatic shuttle loom. The ends and picks density of fabric were 34 and 26, and its weight per square meter was 230grams.

\subsubsection{Alkaline Treatment}

The cellulosic fibre shows positive sign to alkaline treatment up to certain percentage beyond that the strength drops. These processes remove the pectin, oil and other added impurities and enhance absorbency of the fabric. In this research work, the desized fabric was treated with various alkaline concentrations $(\mathrm{NaOH})$, such as $6 \%, 12 \%, 18 \%$ and $24 \%$ for the period of 10 minutes, to increase the wettability of fabric by binder. The alkaline treated fabric was neutralized by souring.

\subsubsection{Resin Treatment}

The medium grade Epoxy resin was coated on the fabric surface evenly and they are stick together to form four layer fabrics. Hand lay-up method was used to fabricate the composite material. The fabrics were layered in three types; all four layers in warp way direction, all four layers in weft way direction and layers in alternate directions. The layered fabrics were compressed for the period of 24 hours and were cured in presence of temperature at $60^{\circ} \mathrm{C}$ and pressure $3 \mathrm{MPa}$ for the period of 10 minutes. After the curing process, test samples were cut to the required sizes prescribed in the ASTM standards.
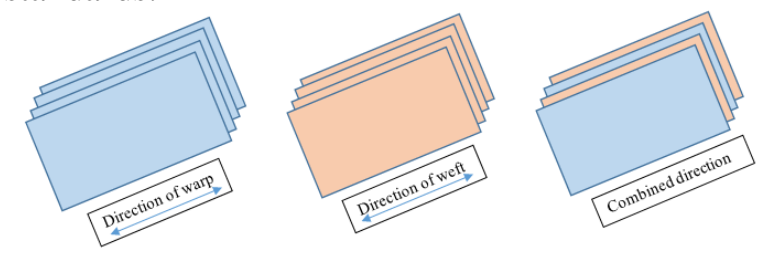

Figure 1. Composite Fabrics

\subsubsection{Testing Methods}

The specimens were conditioned as per ASTM standard D 618. Various mechanical tests such as tensile, flexural and impact were performed on the specimens as per ASTM standard.

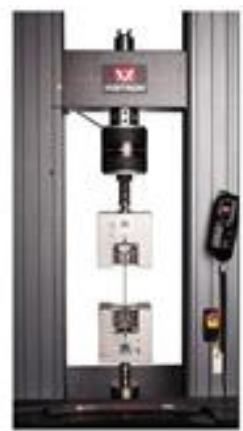

Figure 2. Tensile testing equipment

\subsubsection{Tensile Testing}

ASTM-D 3039 standard was followed to test the tensile testing of multi-layered composite fabrics. The traverse speed was maintained at $2 \mathrm{~mm} / \mathrm{min}$ in Universal Testing Machine. The dimension of composite fabric was $250 \times 25 \mathrm{~mm}$.

\subsubsection{Flexural Testing}

The ASTM-D 790 standard was followed for flexural testing of composite fabric. The test speed was maintained at $1.3-1.5 \mathrm{~mm} / \mathrm{min}$ in Universal Testing Machine. A variety of specimen shapes can be used for this test, but the most commonly used specimen size for ASTM is $125 \mathrm{~mm} \times 12.7 \mathrm{~mm} \times 3.2 \mathrm{~mm}$.

\subsubsection{Impact Testing}

The ASTM-D 256 standard was used for impact test. The dimension of fabric sample was 12.7 $\mathrm{mm} \times 4 \mathrm{~mm} \times 3.2 \mathrm{~mm}$, the sample is allowed to the Izod Impact tester and readings were measured.

\section{RESULTS AND DISCUSSION}

\subsection{Tensile Strength of composite fabrics}

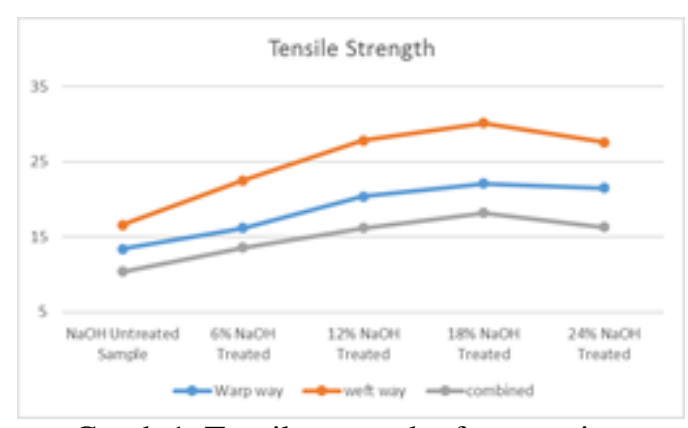

Graph 1. Tensile strength of composites 


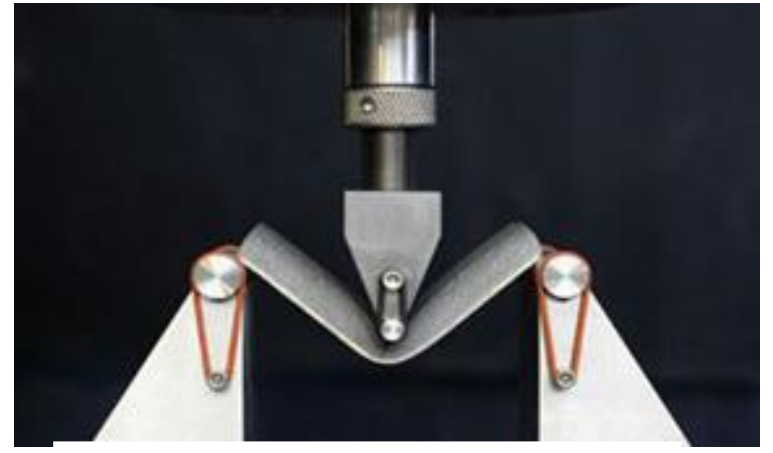

Figure 3. Flexural Testing Equipment

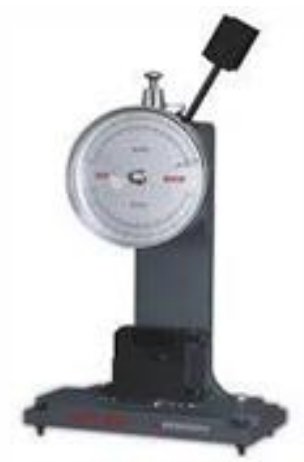

Figure 4. Impact Testing

Table 1. Tensile Strength of Multi-Layer Composites

\begin{tabular}{ccccccc}
\hline & & \multicolumn{5}{c}{ Tensile Strength (MPa) } \\
\cline { 3 - 6 } S.N & Layer & NaOH & $6 \%$ & $12 \%$ & $18 \%$ & $24 \%$ \\
& direction & $\begin{array}{c}\text { Untreate } \\
\text { d Sample }\end{array}$ & $\begin{array}{c}\text { NaOH } \\
\text { Treated }\end{array}$ & $\begin{array}{c}\text { NaOH } \\
\text { Treated }\end{array}$ & $\begin{array}{c}\text { NaOH } \\
\text { Treated }\end{array}$ & $\begin{array}{c}\text { NaOH } \\
\text { Treated }\end{array}$ \\
\hline 1 & Warp way & 13.4 & 16.2 & 20.4 & 22.1 & 21.5 \\
2 & Weft way & 16.6 & 22.5 & 27.8 & 30.1 & 27.6 \\
3 & Combined & 10.4 & 13.6 & 16.2 & 18.2 & 16.3 \\
\hline
\end{tabular}

Table 2. Flexural Strength of Multi-Layer Composites

\begin{tabular}{ccccccc}
\hline & & \multicolumn{5}{c}{ Flexural Strength (MPa) } \\
\cline { 3 - 7 } S.N & Layer & NaOH & $6 \%$ & $12 \%$ & $18 \%$ & $24 \%$ \\
direction & $\begin{array}{c}\text { Untreated } \\
\text { Sample }\end{array}$ & $\begin{array}{c}\mathrm{NaOH} \\
\text { Treated }\end{array}$ & $\begin{array}{c}\mathrm{NaOH} \\
\text { Treated }\end{array}$ & $\begin{array}{c}\text { NaOH } \\
\text { Treated }\end{array}$ & $\begin{array}{c}\text { NaOH } \\
\text { Treated }\end{array}$ \\
\hline 1 & Warp way & 33.6 & 37.2 & 43.8 & 47.7 & 46 \\
2 & Weft way & 36.2 & 44.2 & 48.1 & 52.6 & 52.6 \\
3 & Combined & 27.3 & 30.2 & 29.6 & 34.2 & 34.3 \\
\hline
\end{tabular}

The tensile strength of four layered composite fabrics was shown in Table 1 . The $18 \%$ alkali treated fabric has high tensile strength than other samples. The tensile strength increases with increase in alkali concentration up to $18 \%$ beyond that it decreases. The multi layered fabric prepared from weft way direction shows high tensile strength, due to high modulus and less strain property of flax yarn. In warp and weft way combined multi-layer fabric, all the yarns are not subject to breaking load at the same time.

\subsection{Flexural Strength of Composite Fabrics}

The flexural strength of four layered composite fabrics was shown in Table 2. The flexural strength is directly proportional to the alkali concentration up to $18 \%$. The weft way direction multi-layered fabric shows good

flexural strength. All the threads in the combined multi-layered fabric doesn't subject to load at the simultaneously.

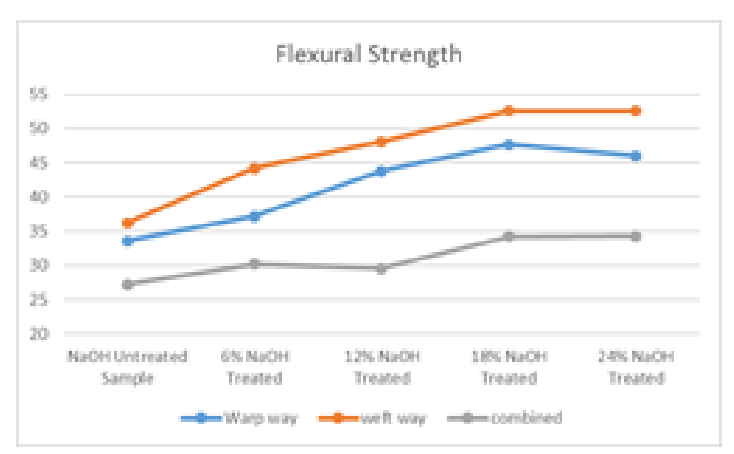

Graph 2. Flexural strength of samples

2.3 Impact Resistance of Composite Fabrics 
The similar effect was observed in increase in alkali percentage on impact resistance of composite fabric. The $18 \%$ alkali treated weft way multi-layered fabric shows superior performance than other samples.

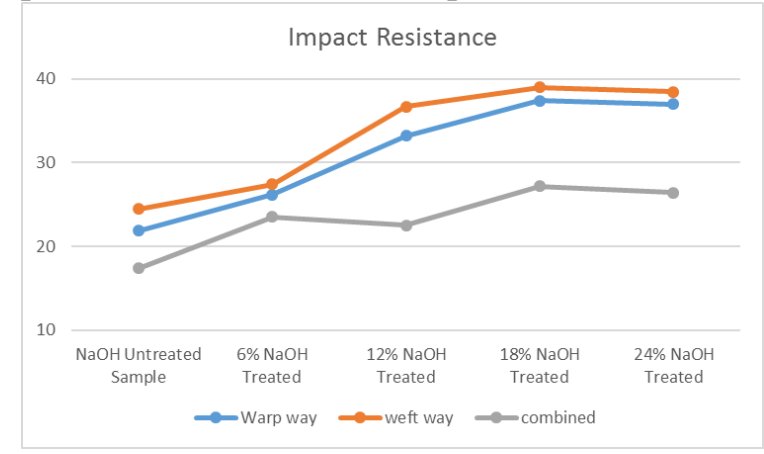

Graph 3. Impact Resistances of Samples

Table 2 shows the results of analysis of variance (strength of composite fabrics). High value of $F$ (44.071), p-value of 0.000 for the factor Alkali concentration and $\mathrm{F}(106.578)$, $\mathrm{p}$ value of 0.000 for the factor lay direction verify that the corresponding null hypothesis is rejected at 5\% level of significance. The increase in alkali concentration and lay direction shows significant impact on the mechanical properties of the fabric. The combined effect of Treatment * Lay direction shows significant impact on the mechanical properties of the fabric at $10 \%$ level of significance.

\section{CONCLUSION}

The application of composite fabrics plays the major role in versatile industrial application such as automobile interiors, filters and concrete structures etc. Most of the application areas require good mechanical properties from composite materials. In this work, some of the mechanical properties such as tensile, flexural and impact resistance were studied, by the use of viscose and flax multi-layer composite fabrics. It was observed that the alkali treated composite fabric shows better mechanical properties up to $18 \%$. All the fabric layers in weft way direction produce enhanced mechanical properties than in other samples.

\section{REFERENCES}

[1]. Venkateshwaran, N., Ayyasamy, E. (2012). Mechanical and Water Absorption Properties of Woven Jute/Banana Hybrid Composites, Fibres and polymers, 13(7) 907-914. doi:10.1007/s12221-012-0907-0
[2]. Senthil kumar., Balachander, S. (2019). Studying the effect of reinforcement parameters on the mechanical properties of natural fibre-woven composites by Taguchi method, Journal of Industrial Textiles. doi: 10.1177/1528083718823292

[3]. Jianxia, Y., Luping, Z., Zhuo Y. (2016). Improving mechanical properties of ramie/poly(lactic acid) composites by synergistic effect of fabric cyclic loading and alkali treatment', Journal of Industrial Textiles, 47(3) 390-407. doi:10.1177/1528083716648763

[4]. Ezazul Fahmee Ahmad Jamal, et al. (2018). Optimization of alkali treatment condition on tensile properties of kenaf reinforced polyester composite using response surface method, International Journal of Integrated Engineering, 10(1) 40-46. doi: 10.30880/ijie.2018.10.01.007

[5]. Gibi Kannan, T., Chang, M.W., Kuo Bing, C. (2012). Effect of reinforcement on the mechanical and thermal properties of flax/polypropylene interwoven fabric composites, Journal of Industrial Textiles, 42(4) 417-433.

[6]. Sakthivel, M., Ramesh, S. (2013). Mechanical properties of natural fibre polymer composites, Science park, 1(1).

[7]. Khoshbakht, M., Choudary, S.J., Seif, M.A., Khashaba, U.A. (2009). Failure of woven composites under combined tension-bending loading, Composite Structures, Vol.90, pp 279-286.

[8]. Padma priya, S., Rai, S.K. (2006). Mechanical performance of biofiber/glass-reinforced epoxy hybrid composites, Journal of Industrial Textiles, 35(3) 217-226. 